\title{
(t) Jmat
}

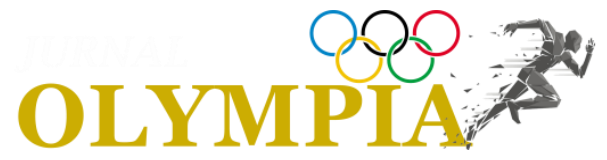

\section{Penguasaan Keterampilan Dasar Bermain Futsal Pada Siswa U-15 Akademi Futsal GMS Kabupaten Lahat Sumatera Selatan}

\author{
Taufik Novianto ${ }^{1}$, Ginanjar Nugraheningsih ${ }^{2}$
}

Universitas Mercu Buana, Yogyakarta, Indonesia ${ }^{1,2}$

\section{Info Artikel \\ Sejarah Artikel: \\ Diterima Desember 2021 \\ Disetujui Februari 2021 \\ Dipublikasikan Maret 2021}

Keywords:Peforma, Keterampilan Dasar, Bermain Futsal, Akademi Futsal

\begin{abstract}
Abstrak
Penelitian ini bertujuan mengetahui tingkat keterampilan dasar bermain futsal siswa Akademi Futsal GMS di Kabupaten Lahat Sumatera Selatan. Metode yang digunakan adalah survei dengan tes dan pengukuran. Jenis penelitian ini adalah penelitian deskriptif kuantitatif. Subjek yang digunakan dalam penelitian ini adalah siswa Akademi Futsal GMS di Kabupaten Lahat Sumatera Selatan yang berjumlah 21 siswa putra U-15 dan merupakan penelitian populasi (total sampling). Instrumen yang digunakan adalah tes keterampilan bermain futsal (Agus Susworo, Saryono, \& Yudanto 2009) melalui uji validitas dan reliabilitas instrumen. Analisis data menggunakan teknik analisis statistik deskriptif yang dituangkan dalam bentuk persentase (\%). Hasil dari penelitian ini ditemukan bahwa tingkat keterampilan dasar bermain futsal siswa Akademi Futsal GMS Kabupaten Lahat Sumatera Selatan berada pada kategori "sangat kurang" sebesar 9,52\% (2 siswa), kategori "kurang" sebesar 23,81\% (5 siswa), kategori “cukup" sebesar $23,81 \%$ (5 siswa), kategori "baik" sebesar 38,10\% (8 siswa), dan kategori "sangat baik" 4,76\% (1 siswa). Sehingga disimpulkan tingkat keterampilan dasar bermain futsal siswa akademi futsal U-15 GMS Kabupaten Lahat Sumatera Selatan termasuk pada kategori "BAIK" yaitu $38,10 \%$ dengan rata-rata 45,46. Dengan demikian siswa akademi futsal U-15 GMS Kabupaten Lahat Sumatera Selatan pada saat latihan rata-rata sudah mendapat latihan keterampilan teknik dasar futsal secara menyeluruh, yang meliputi: teknik passing, controlling, dribbling, dan shooting sudah baik.
\end{abstract}

\begin{abstract}
This study aims to determine the basic skill level of playing futsal of GMS Futsal Academy students in Lahat Regency, South Sumatra. The method used is a survey with tests and measurements. This type of research is descriptive quantitative research. The subjects used in this study were students of the GMS Futsal Academy in Lahat Regency, South Sumatra, totaling 21 male U-15 students and a population study (total sampling). The instrument used is a test of futsal playing skills
\end{abstract}




(Agus Susworo, Saryono, \& Yudanto 2009) through a test of the
validity and reliability of the instrument. Data analysis used
descriptive statistical analysis techniques as outlined in the form of
percentages (\%). The results of this study found that the basic skill
level of playing futsal students of the GMS Futsal Academy, Lahat
Regency, South Sumatra was in the "very poor" category of 9.52\% (2
students), "less" category of $23.81 \%$ (5 students), the "enough"
category is $23.81 \%(5$ students), the "good" category is $38.10 \%(8$
students), and the "very good" category is $4.76 \%(1$ student). So, it can
be concluded that the basic skill level of playing futsal of the U-15
GMS futsal academy students in Lahat Regency, South Sumatra is
included in the "GOOD" category, which is 38.10\% with an average of
45.46. Thus, students of the U-15 GMS Futsal Academy, Lahat
Regency, South Sumatra, during practice, on average, had received
basic futsal technical skills training, which included: passing,
controlling, dribbling, and shooting techniques were good.

E-mail: mohammedtaufik32@gmail.com ${ }^{1}$

ginanjar@mercubuana-yogya.ac.id ${ }^{2}$
ISSN 2656-5994(online)

ISSN 2656-5986 (cetak)

\section{PENDAHULUAN}

Banyak olahraga yang dapat memberikan perkembangan jasmani, mental sosial dan emosional terhadap perkembangan anak usia dini, salah satunya adalah futsal. Futsal merupakan permainan regu terdiri atas 5 lawan 5, dan produktivitas setiap gol pertandingannya sangat cepat sehingga olahraga ini nyaman untuk digeluti. Menang atau kalah dalam pertandingan dilihat dari tingkat baik buruknya pemain serta proses strategi dalam pertandingan. Menurut (Sugawara \& Nikaido, 2014) futsal adalah salah satu cabang olahraga yang termasuk dalam permainan bola besar. Olahraga futsal yang dimainkan di dalam ruangan adalah olahraga berupa team dengan sifat dinamis. Menurut (Naser et al., 2017) futsal adalah sebuah versi sepakbola yang dimainkan di dalam ruangan lima melawan lima (satu penjaga gawang dan lima sebagai pemain) yang telah disetujui oleh badan pengatur sepak bola internasional atau yang biasa disebut FIFA. Menurut (Almeida et al., 2019) analisis permainan futsal semestinya tidak hanya mencakup aksi permainan di lapangan khususnya pola atau strategi untuk menciptakan gol. Olahraga futsal mempunyai kesamaan dengan sepakbola, salah satunya memiliki tujuan untuk merebut bola dari penguasaan lawan dan memasukan bola sebanyak mungkin, serta menjaga pertahanan sehingga tidak kemasukan gol dan pemenang diketahui dari total gol tercipta. Walaupun futsal dan sepak bola memiliki kesamaan namun ada beberapa yang membedakan seperti ukuran lapangan, peralatan, jumlah pemain, dsb. Penulis menyimpulkan bahwa permaianan futsal adalah permainan beregu yang masing-masing terdiri atas lima orang 
pemain. Permainan futsal merupakan hasil dari adopsi olahraga sepakbola yang telah dimodivikasi menjadi sebuah permainan yang dilakukan hanya dengan lima orang di setiap team dan memerlukan penguasaan keterampilan teknik yang baik. Permainan futsal merupakan adopsi sepakbola yang telah dimodivikasi menjadi sebuah permainan dan memiliki tujuan yang sama yaitu merebut bola dari penguasaan lawan dan juga mencetak gol sebanyak banyaknya ke gawang dengan melibatkan seluruh tubuh tidak termaksud tangan.

Sebagai basik teknik futsal, seorang pemain futsal harus menguasai teknik gerakan tanpa bola, teknik passing, teknik dribbling, teknik control, teknik shooting (Wibowo, 2019) Akademi Futsal GMS merupakan sekolah olahraga non formal yang menerapkan kurikulum pembelajaran futsal menjadi olahraga utama yang dipelajari baik teori maupun praktek. Kegiatan Akademi Futsal GMS dilaksanakan pada hari Selasa dan Kamis jam 2 setiap minggunya. Akademi futsal menjadi sarana untuk mengembangkan keterampilan dasar permainan futsal, seperti mengiring, menendang, menyundul dan menyerang. Bagi anak-anak ataupun remaja, futsal mampu mengembangkan skill dan insting bermain bola. Setiap individu mempunyai tingkat keterampilan yang berbeda-beda dalam bermain futsal. Ada yang baik dan ada juga yang kurang baik. Misalnya kemampuan teknik dasar siswa Akademi Futsal GMS Kabupaten Lahat Sumatera Selatan yang terlihat seperti masih kurang terarah sehingga permainan futsal mereka tidak berkembang. Hal ini dapat diamati dari observasi di lapangan ditemui beberapa siswa yang melakukan passing dengan tendangan terlalu lemah, sehingga hasil yang didapat tidak sesuai arah yang diinginkan dan juga sering kali dipotong oleh lawan, sehingga saat mengumpan bola kepada teman sering terjadi kesalahan. Ditemui keterampilan beberapa siswa melakukan dribbling yang belum baik, sering terlepas sehinga bola mudah dikuasai lawan dan shotting kurang akurat, tidak tepat sasaran dan tidak terarah khususnya ketika siswa Akademi Futsal GMS menghasilkan gol.

Pembinaan olahraga prestasi melalui sentra-sentra pembinaan di daerah memang tidak bisa dipisahkan dari olahraga pendidikan. Peran olahraga pendidikan selain sebagai media pendidikan namun juga bertujuan memberikan keluasaan pengalaman gerak. Hal ini dirasa perlu agar ketika berlatih teknik dasar siswa mudah cepat menguasai karena otot mempunyai pengalaman gerak yang diberikan ketika di sekolah. Hasil studi literatur beberapa contoh olahraga pendidikan antara lain modifikasi permainan sepakbola bagi siswa SMA penderita asma (Wibowo, 2013), pengembangan aktivitas fisik terprogram melalui permainan sirkuit anak usia dini (Taroreh, 2017), program aktivitas fisik manipulatif berbasis kinestetik untuk anak usia 6 tahun (Taroreh \& Wijaya, 2020), aktifitas bermain dapat meningkatkan gerak dasar anak tuna grahita ringan (Haris Satria dkk., 2020), permainan tradisional sebagai

Taufik Novianto ${ }^{1}$, Ginanjar Nugraheningsih ${ }^{2} /$ Jurnal Olympia Vol 3(1) (2021)

Judul: Penguasaan Keterampilan Dasar Bermain Futsal Pada Siswa U-15 Akademi Futsal GMS Kabupaten Lahat 
materi pembelajaran atletik di Sekolah Dasar (Musiandi \& Taroreh, 2020), permainan CBA (Culture Based Athletic) pada pembelajaran atletik sebagai solusi alternatif melestarikan permainan tradisional di Sumatera Selatan (Taroreh \& Satria, 2020), instrumen penilaian sebagai contoh model penilaian kinerja hasil pembelajaran permainan bola voli di sekolah dasar (Taroreh, 2012), berbagai model pembelajaran lari jarak pendek pada siswa SMP (Mayanto dkk., 2021), media Flash Card untuk pembelajaran lari di Sekolah Menengah Atas (Nahar \& Taroreh, 2020).

Berdasarkan observasi peneliti ada aspek fisik, teknik, mental dan taktik yang perlu diperhatikan untuk menjadi atlet. Hal ini juga sesuai pendapat Nugraheningsih dan Saputro bahwa empat hal yang perlu diperhatikan dalam pencapaian maksimal atlet yaitu fisik, teknik, mental dan taktik (Nugraheningsih \& Saputro, 2019). Untuk itu dari permasalahan yang ditemukan di lapangan maka penulis tertarik melakukan penelitian terkait keterampilan teknik dasar bermain futsal.

Sehingga dari latar belakang masalah penulis merumuskan masalah dalam penelitian ini yaitu "Bagaimana tingkat keterampilan dasar bermain futsal siswa Akademi Futsal GMS U-15 Kabupaten Lahat Sumatera Selatan?" menjadi suatu bahan kajian yang menarik untuk diteliti. Selain itu belum pernah adanya penelitian yang serupa dilakukan untuk mengetahui tingkat keterampilan dasar bermain futsal siswa Akademi Futsal GMS U-15 Kabupaten Lahat Sumatera Selatan.

\section{METODE PENELITIAN}

Metode yang digunakan adalah survei dengan tes dan pengukuran. Jenis penelitian ini adalah penelitian deskriptif kuantitatif. Menurut (Sugiyono, 2012) penelitian survei merupakan penelitian yang biasa dilakukan untuk subyek penelitian yang banyak dimaksudkan untuk mengumpulkan pendapat atau informasi mengenai tujuan penelitian ini adalah untuk mengetahui tingkat keterampilan dasar bermain futsal siswa Akademi GMS $\mathrm{U} 15$.

Populasi dalam penelitian ini adalah seluruh siswa Akademi Futsal U-15 GMS Kabupaten Lahat Sumatera Selatan yang berjumlah 21 siswa. Teknik penarikan sampel dalam penelitian ini yaitu total sampling, seluruh anggota populasi dijadikan sampel sejumlah 21 siswa Akademi Futsal U-15 GMS Kabupaten Lahat Sumatera Selatan.

Instrumen penelitian menurut (Arikunto, 2013) adalah alat bantu yang dipilih dan digunakan oleh peneliti dalam kegiatannya mengumpulkan data agar kegiatan tersebut menjadi sistematis dan dipermudah olehnya. Instrumen yang yang digunakan adalah Tes Futsal FIK Yogyakarta yang dikutip dari Tes Keterampilan Bermain Futsal (Agus Susworo \& Saryono, 2009). Tes yang disusun untuk mengukur keterampilan dasar bermain futsal meliputi: passing, controlling, dribbling dan shooting memiliki nilai Validitas tes sebesar 0,6666 dan Reliabilitas tes sebesar 0,6911. 
Teknik analisis data yang digunakan dalam penelitian ini adalah analisis deskriptif kuantitatif dengan persentase. Analisis kuantitatif adalah analisis yang berbasis pada kerja hitung-menghitung angka (Arikunto, 2010). Kemudian data hasil dari masingmasing tes dapat diambil suatu kesimpulan. Menghitung persentase digunakan rumus sebagai berikut:

$$
\mathrm{P}=\mathrm{f} / \mathrm{N} \times 100 \%
$$

Keterangan:

$$
\begin{array}{ll}
\mathrm{P} & \text { : Persentase } \\
\mathrm{f} & \text { : Jumlah kategori } \\
\mathrm{N} & \text { : Jumlah keseluruhan Atlet }
\end{array}
$$

\section{HASIL DAN PEMBAHASAN}

Dari test yang telah dilakukan pada siswa Akademi Futsal U-15 GMS Kabupaten Lahat Sumatera Selatan diperoleh hasil penelitian tingkat keterampilan dasar bermain futsal Siswa Akademi Futsal U-15 GMS Kabupaten Lahat Sumatera Selatan seperti pada tabel deskriptif statistik berikut ini:

Tabel 1. Descriptive Statistics

\begin{tabular}{l|r}
\multicolumn{2}{c}{ U-15 } \\
\hline \multicolumn{1}{c|}{$\mathrm{N} \quad$ Valid } & 21 \\
\cline { 2 - 3 } Mean & 0 \\
\hline Median & 45.4629 \\
\hline Mode & 24.2200 \\
\hline Std. Deviation & 8.85159 \\
\hline Variance & 78.351 \\
\hline Range & 35.09 \\
\hline Minimum & 24.20 \\
\hline Maximum & 59.29 \\
\hline Sum & 954.72 \\
\hline \multicolumn{2}{c}{$\begin{array}{c}\text { a. Multiple modes exist. The } \\
\text { smallest value is shown }\end{array}$}
\end{tabular}

Berdasarkan tabel 1 diperoleh deskriptif data hasil penelitian dari n: 21 diperoleh mean sebesar 45,46, median sebesar 47,22, mode sebesar 24,20, standar deviasi sebesar 8,85, variance sebesar 78,35, range sebesar 35,09, nilai minimum sebesar 24,20 , nilai maksimum sebesar 59, 29 dan sum sebesar 954,72.

Tabel 2. Distribusi Frekuensi Tingkat Keterampilan Dasar Bermain Futsal Siswa Akademi Futsal U-15 GMS Kabupaten Lahat Sumatera Selatan

\begin{tabular}{ccccc}
\hline No & Interval & Kategori & Frek & $\%$ \\
\hline 1 & $58,735<\mathrm{X}$ & Sangat Baik & 1 & $4,76 \%$ \\
2 & $49,885<\mathrm{X} \leq 58,735$ & Baik & 8 & $38,1 \%$ \\
3 & $41,035<\mathrm{X} \leq 49,885$ & Cukup & 5 & $23,81 \%$ \\
4 & $32,185<\mathrm{X} \leq 41,035$ & Kurang & 5 & $23,81 \%$ \\
5 & $\mathrm{X} \leq 32,185$ & Sangat & 2 & $9,52 \%$ \\
& & Kurang & & \\
\hline \multicolumn{2}{c}{ Jumlah } & & 21 & $100 \%$ \\
\hline
\end{tabular}

Selanjutnya data pada tabel 1 digunakan untuk mencari tingkat keterampilan dasar bermain futsal siswa Akademi Futsal GMS U15 Kabupaten Lahat Sumatera Selatan menggunakan 5 (lima) rentang interval PAN (Penilaian Acuan Norma) dengan tabel distribusi frekuensi yang memiliki kriteria: sangat kurang, kurang, cukup, baik dan sangat baik seperti pada tabel 2 secara detail disajikan dalam gambar histogram sebagai berikut:

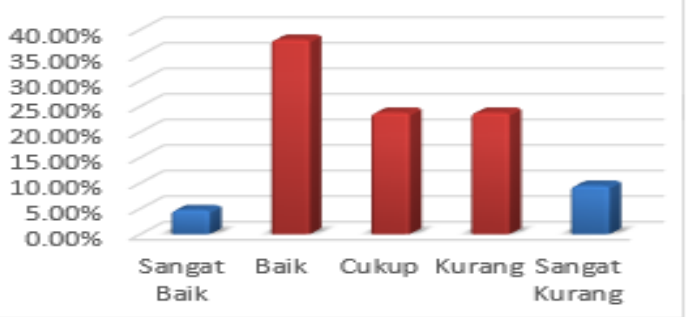

Gambar 1. Penyajian Diagram Tingkat Keterampilan Dasar Bermain Futsal Siswa 
Akademi Futsal U-15 GMS Kabupaten Lahat Sumatera Selatan

Berdasarkan tabel 2 dan gambar 1 diagram tingkat keterampilan dasar bermain futsal siswa akademi futsal U-15 GMS Kabupaten Lahat Sumatera Selatan menunjukkan hasil penelitian yang diperoleh yaitu kategori "sangat kurang" sebesar 9,52\% (2 siswa), kategori "kurang" sebesar 23,81\% (5 siswa), kategori “cukup" sebesar 23,81\% (5 siswa), kategori "baik" sebesar 38,10\% (8 siswa), dan kategori "sangat baik" 4,76\% (1 siswa). Sehingga disimpulkan tingkat keterampilan dasar bermain futsal siswa akademi futsal U-15 GMS Kabupaten Lahat Sumatera Selatan termasuk pada kategori "BAIK" yaitu $38.10 \%$ dengan rata-rata 45,46.

Dengan demikian siswa akademi futsal U-15 GMS Kabupaten Lahat Sumatera Selatan pada saat latihan rata-rata sudah mendapat latihan keterampilan teknik dasar futsal secara menyeluruh, yang meliputi: teknik passing, controlling, dribbling, dan shooting sudah baik.

Tingkat keterampilan dasar bermain futsal siswa akademi futsal U-15 GMS Kabupaten Lahat Sumatera Selatan termasuk pada kategori "BAIK" yaitu 38,10\% dengan rata-rata 45,46. Dengan demikian siswa akademi futsal U-15 GMS Kabupaten Lahat Sumatera Selatan pada saat latihan rata-rata sudah mendapat latihan keterampilan teknik dasar futsal secara menyeluruh, yang meliputi: teknik passing, controlling, dribbling, dan shooting sudah baik.
Permainan futsal dapat berlangsung lancar, teratur dan menarik apabila pemain menguasai unsur-unsur dalam permainan futsal salah satunya adalah penguasaan keterampilan teknik dasar bermain futsal yang baik. Teknik dasar yang harus dikuasai oleh pemain futsal adalah dribbling, controlling, shooting dan passing. Passing tujuannya untuk memberikan atau mengoper bola kepada teman. Passing yang baik sangat dibutuhkan dalam bermain futsal, karena dengan menguasai teknik ini maka dapat mempermudah teman kita untuk menerima bola. Dribbling dan controlling juga penting dalam permainan futsal, karena dapat digunakan untuk penyerangan dengan membawa bola mendekati gawang lawan. Menurut (Asmar Jaya, 2008) Dribbling merupakan menendang bola terputus-putus atau pelan-pelan. Dribbling bertujuan untuk mendekati jarak ke sasaran, melewati lawan, dan menghambat permainan. Hal ini diimbangi dengan Teknik controlling bola yang baik supaya bola lebih terarah dan tidak mudah lepas. Shooting juga sangat penting dalam permainan futsal karena tujuan utamanya untuk menciptakan gol. Pemain yang memiliki shooting yang baik dan akurat akan mudah untuk menciptakan gol terutama pada saat melakukan pinalti. Menurut (Lhaksana, 2011) shooting merupakan cara untuk menciptakan gol. Penguasaan shooting yang baik akan mempermudah menciptakan gol atau memasukkan bola ke gawang lawan.

Keterampilan teknik-teknik dasar ini diperlukan dalam permainan futsal untuk 
menghasilkan hasil permainan futsal yang maksimal dalam sebuah team. Tingkat keterampilan dasar bermain futsal siswa akademi futsal U-15 GMS Kabupaten Lahat Sumatera Selatan termasuk pada kategori "BAIK" yaitu $38.10 \%$ dengan rata-rata 45,46. Dengan demikian siswa akademi futsal U-15 GMS Kabupaten Lahat Sumatera Selatan pada saat latihan rata-rata sudah mendapat latihan keterampilan teknik dasar futsal secara menyeluruh, yang meliputi: teknik passing, controlling, dribbling, dan shooting sudah baik.

\section{SIMPULAN}

Hasil dari penelitian ini ditemukan bahwa tingkat keterampilan dasar bermain futsal siswa Akademi Futsal GMS Kabupaten Lahat Sumatera Selatan berada pada kategori "sangat kurang" sebesar 9,52\% (2 siswa), kategori "kurang" sebesar 23,81\% (5 siswa), kategori "cukup" sebesar 23,81\% (5 siswa), kategori "baik" sebesar 38,10\% (8 siswa), dan kategori "sangat baik" 4,76\% (1 siswa). Sehingga disimpulkan tingkat keterampilan dasar bermain futsal siswa akademi futsal U15 GMS Kabupaten Lahat Sumatera Selatan termasuk pada kategori "BAIK" yaitu $38.10 \%$ dengan rata-rata 45,46. Dengan demikian siswa akademi futsal U-15 GMS Kabupaten Lahat Sumatera Selatan pada saat latihan ratarata sudah mendapat latihan keterampilan teknik dasar futsal secara menyeluruh, yang meliputi: teknik passing, controlling, dribbling, dan shooting sudah baik.

\section{DAFTAR PUSTAKA}

Agus Susworo, D. M., \& Saryono. (2009). Tes Keterampilan Dasar Bermain Futsal. Jurnal IPTEK Olahraga.

Akis Mayanto, Muhamad Syamsul Taufik, Adi Wijayanto, Soleh Solahuddin, \& Bangkit Seandi Taroreh. (2021). Model Pembelajaraan Jarak Pendek Pada Siswa Sekolah Menengah Pertama. Jurnal Kejaora (Kesehatan Jasmani Dan Olah Raga), 6(1), 114-120. https://doi.org/10.36526/kejaora.v6i1.11 74.

Almeida, J., Sarmento, H., Kelly, S., \& Travassos, B. (2019). Coach decisionmaking in Futsal: from preparation to competition. International Journal of Performance Analysis in Sport, 19(5). https://doi.org/10.1080/24748668.2019.1 $\underline{648717}$

Arikunto. (2010). Suharsimi Arikunto.pdf. In Prosedur Penelitian Suatu Pendekatan Praktik-Revisi ke X.

Arikunto, S. (2013). Metodologi penelitian. Bumi Aksara.

Asmar Jaya. (2008). Futsal Gaya Hidup, Peraturan dan Tips-Tips Permainan. In Futsal Gaya Hidup, Peraturan dan TipsTips Permainan.

Lhaksana, J. (2011). Futsal Modern. Swadaya Group.

Musiandi, T., \& Taroreh, B. S. (2020). Pengembangan Pembelajaran Atletik Melalui Pendekatan Permainan Tradisional Sumatera Selatan. Jurnal Olympia, 2(1), 29-37. https://doi.org/10.33557/jurnalolympia.v $\underline{2 \mathrm{i} 1.885}$.

Nahar, A., \& Taroreh, B. (2020). Pengembangan Model Pembelajaran Lari Melalui Media Flash Card di Sekolah Menengah Atas. Jurnal Olympia, 2(2), 34-41. Retrieved from http://journal.binadarma.ac.id/index.php/ olympia/article/view/1266. 
Naser, N., Ali, A., \& Macadam, P. (2017). Physical and physiological demands of futsal. In Journal of Exercise Science and Fitness (Vol. 15, Issue 2). https://doi.org/10.1016/i.jesf.2017.09.00 1 .

Nugraheningsih, g., \& saputro, y. A. (2019). Peningkatan kesegaran jasmani melalui matakuliah pencaksilat mahasiswa ilmu keolahragaan. Jp.Jok (Jurnal Pendidikan Jasmani, Olahraga Dan Kesehatan). https://doi.org/10.33503/jp.jok.v3i1.56

Satria, M. H., Taroreh, B. S., Melynda, M., \& Asri, N. (2020). Play Activity: To Increase Fundamental Movement Skill for Children with Mild Mental Retardation. International Journal of Human Movement and Sports Sciences, $8(6 \mathrm{~A})$, $1-10$. https://doi.org/10.13189/saj.2020.08070 $\underline{1 .}$

Sugawara, E., \& Nikaido, H. (2014). Properties of AdeABC and AdeIJK efflux systems of Acinetobacter baumannii compared with those of the AcrAB-TolC system of Escherichia coli. Antimicrobial Agents and Chemotherapy, 58(12), 7250-7257. https://doi.org/10.1128/AAC.03728-14.

Sugiyono. (2012). Metode Penelitian Kuantitatif, Kualitatif dan R \& D.Bandung:Alfabeta. Metode Penelitian Kuantitatif, Kualitatif Dan $R \quad \&$ D.Bandung:Alfabeta. https://doi.org/10.1017/CBO9781107415 324.004 .

Taroreh, B. S. (2012). Model Performance Assesment of Learning Outcomes of Volleyhool Ball in Elementary School. Journal of Physical Education and Sports, 1(2), 79-86. https://doi.org/10.15294/JPES.V1I2.80.

Taroreh, B. S. (2017). Development Model Approach Through Exercise Kinesthetic Game Circuit for Children Ages 4-6 Years. JIPES - Journal of Indonesian Physical Education and Sport, 3(1), 41. https://doi.org/10.21009/JIPES.031.06.
Taroreh, B. S., \& Satria, M. H. (2020). Implementasi Permainan CBA pada Pembelajaran Atletik sebagai Solusi Alternatif Melestarikan Permainan Tradisional di Sumatera Selatan. Jurnal Curere, 4(1). https://doi.org/10.36764/jic.v4i1.348.

Taroreh, B. S., \& Wijaya, M. A. (2020). Program Aktivitas Fisik Manipulatif Berbasis Kinestetik Untuk Anak Usia 6 Tahun. Jurnal Penjakora, 7(1), 1-10. https://doi.org/10.23887/penjakora.v7i1

Wibowo, A., \& Kushartanti, W. (2013). Modifikasi Permainan Sepakbola bagi Siswa SMA Penderita Asma. Jurnal Keolahragaan, $\quad$ 1(2), 104-119. https://journal.uny.ac.id/index.php/jolahr aga/article/view/2567/2121.

Wibowo, A. T. (2019). Keterampilan Dasar Permainan Futsal (1st ed.). Mbrige Press. 